\title{
Flower Development of Ornamental Crabapple According to BBCH Scale
}

\author{
Tabita-Teodora LISANDRU ${ }^{1}$, Adrian FÜSTÖS ${ }^{1}$, Adelina DUMITRAȘ ${ }^{1}$, Viorel MITRE ${ }^{1 *}$ \\ ${ }^{1}$ University of Agricultural Sciences and Veterinary Medicine, 3-5 Mănăștur St., 400372 Cluj-Napoca, \\ Romania. \\ *Corresponding author, e-mail: mitreviorel@yahoo.com
}

Bulletin UASVM Horticulture 74(2)/ 2017

Print ISSN 1843-5254, Electronic ISSN 1843-5394

DOI:10.15835/buasvmcn-hort: 0041

\begin{abstract}
Crabapples offer a wide variety of tree forms and size, leaf shapes, flowers and colourful fruits which improve the quality of green spaces, being an excellent four-season landscape trees. The aim of this study was to determine flower development of Malus x zumi 'Professor Sprenger' using Biologische Bundesantalt, Bundessortenamt, and Chemische Industrie - BBCH code under urban conditions. Observations were made weekly during two growing seasons to identify the flowering stages. Flower development of ornamental crabapple described according to $\mathrm{BBCH}$ scale started from flower induction until dormancy. Knowing the flower development stages of 'Professor Sprenger' variety provide information on visual assessment protocols from urban areas and determine the species' most ornamental period of the year.
\end{abstract}

Keywords: $B B C H$ code, flower stages, Malus x zumi 'Professor Sprenger'

\section{Introduction}

Crabapples (Malus sp.) are well known for their ornamental values which make them to be constantly used in urban design. They have specific effects and impacts for landscape settings (Draper, 2006). Crabapples have a variety of tree forms and size, leaves shapes, flowers and colourful fruits which contributes to the visual quality of urban green spaces. From spring bloom to attractive colours of the leaves in autumn and colourful fruits till winter, crabapples are excellent for long season interest (Shawn, 2006).

\section{Materials and Methods}

The aim of the current work was to determine the phenological growth stages of Malus $\mathrm{x}$ zumi 'Professor Sprenger' using Biologische Bundesantalt, Bundessortenamt, and Chemische Industrie - BBCH code and to describe the development process of the species under urban conditions. Data were collected from the experimental orchard of the University of
Agricultural Sciences and Veterinary Medicine from Cluj-Napoca (Romania). Malus $x$ zumi 'Professor Sprenger' fruit trees were selected in order to perform this study. Visual observations and photographs were carried out weekly during two growing seasons (2016-2017) in order to characterise flower development and to determine the period of the year in which 'Prof Sprenger' is the most decorative. Photographs of the flower stage development were taken using a professional camera.

\section{Results and Discussions}

Flower development in ornamental crabapple described according to $\mathrm{BBCH}$ scale started from flower induction till dormancy. First stage was bud dormancy (stage 00) and last stage was total leaf drop (stage 97). At the beginning of April, first sepals appear and open and separate in an angle of $120^{\circ}$. Full bloom of 'Professor Sprenger' cultivar appear in the middle of the April, after 4-6 weeks from bud burst, and lasted for two weeks. In this 
Tab. 1. Flower development stages of Malus x zumi 'Professor Sprenger' according to the BBCH code

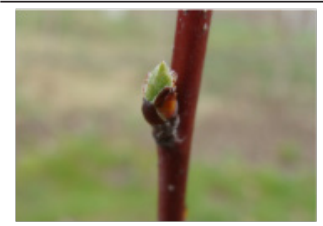

BBCH Code 03

End of leaf bud swelling: bud scales light coloured with some parts densely covered by hairs

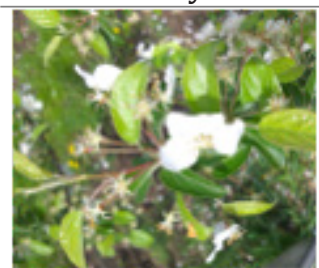

BBCH Code 67

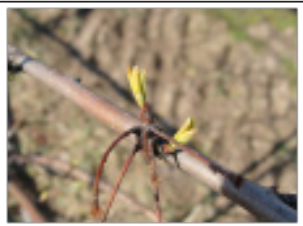

BBCH Code 10

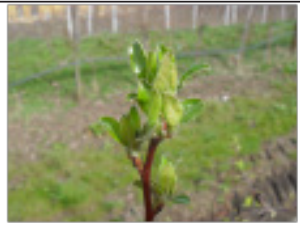

BBCH Code 19

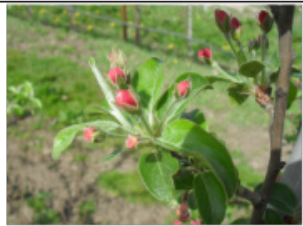

BBCH Code 59

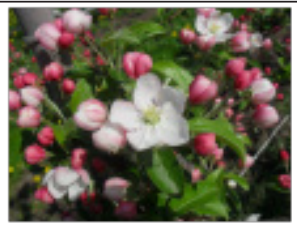

BBCH Code 63

Mouse-ear stage:

Green leaf tips 10

$\mathrm{mm}$ above the bud

scales; first leaves separating

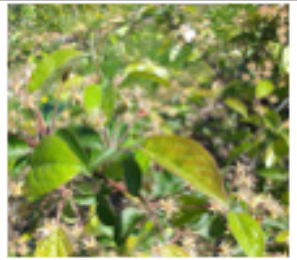

BBCH Code 69

Flowers fading: majority of petals fallen

End of flowering: all petals fallen

\section{First leaves fully expanded}

\section{Most flowers with petals forming a hollow ball}

About $30 \%$ of flowers open

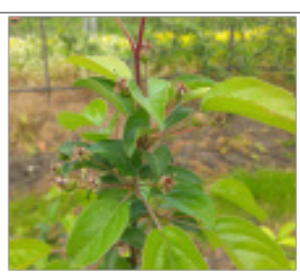

BBCH Code 71

Fruit size up to 10 $\mathrm{mm}$; fruit fall after flowering

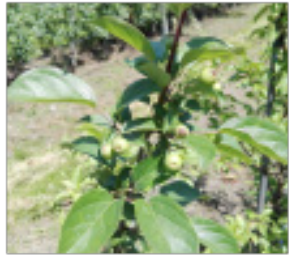

BBCH Code 74

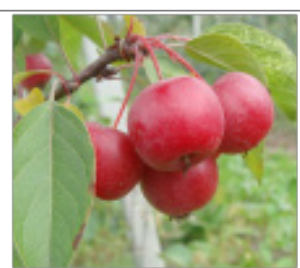

BBCH Code 85

Fruit diameter up to increase in intensity $40 \mathrm{~mm}$; fruit erect of cultivar-specific colour

period of the year crabapple 'Professor Sprenger' is very decorative. The differences between these two growing seasons was insignificant. The blooming time of this species is the most attractive for the users of public green spaces because of the abundance of white flowers. Association of this species with another ornamental plant for creating a wonderful visual perception of the greenery, can be done according to the blooming period of those species.

In table 1 there are presented in detail Malus x zumi 'Professor Sprenger' flower development, starting from leaf bud and ending with fruit development. Each photograph corresponds to a code which describe the flower stage according to the BBCH scale.

\section{Conclusion}

Phenological growth stages in general are effective tools for large cities. It leads to under- standing the pollination, ecosystem functions and flowering process of the tree species. Flower development of Malus x zumi 'Professor Sprenger' according to $\mathrm{BBCH}$ scale have not been reported before. Knowing the development stages of 'Professor Sprenger' variety offer information on visual assessment protocols from urban areas and helps to understand the tree development process under urban conditions. Also, helps to highlight the beauty of this species by choosing the right plants to associate with in green spaces landscape design.

\section{REFERENCES}

1. Draper E, Chatfield J, Cochran K (2006). A Collection of Crabapple Knowledge from Secrest Arboretum: 1993-2005, University/Ohio Agricultural Research and Development Center

2. Wright S, Bergefurd B, Boggs J, Chatfield J, Miller L (2006). Ornamental Crabapple (Malus sp.) Phenology in Southern Ohio, University/Ohio Agricultural Research and Development Center 